\title{
Results of a pilot study of endoscopic screening of first degree relatives of colorectal cancer patients in Italy
}

Laura Colombo, Gianluigi Corti, Filippo Magrì, Alessandro Marocchi, Paolo Brambilla, Carla Crespi, Luigi Manieri, Sergio Ghezzi, Daniela Giannone, Luca Merlino, Paolo Mocarelli

\begin{abstract}
Study objective-Screening recommendations for colorectal cancer include sigmoidoscopy in asymptomatic, average risk persons aged 50 and over and colonoscopy every three to five years in high risk groups. Little is known about the eligible population's compliance with endoscopic screening. This is the first Italian report of an endoscopic screening programme for colorectal cancer patients' relatives.

Design-In 1986, a pilot project for colorectal cancer screening by endoscopy in high risk subjects was started in the Desio (Milan, Italy) public health service region. The results obtained after seven years are described.

Setting-The names of 536 inhabitants with colorectal cancer diagnosed between January 1975 and December 1984 and their relatives' addresses were obtained from the Regione Lombardia Health System records and from the municipal registry offices respectively.

Participants-From October 1986 to October 1993, 778 first degree relatives aged 20-75 were offered colonoscopy.

Main results-After seven years, 233 (29.9\%) had undergone endoscopic examination, mostly up to the splenic flexure. Being $>60$ in age at the start of the programme negatively affected participation $(p<0.05)$. Two cancers were detected and adenomatous polyps were found in another 24 of those screened (frequencies: $0.9 \%$ and $10.3 \%$ respectively). Male gender $(p<0.05)$, increasing age in males $(p<0.01)$, and two or more affected relatives in females $(p<0.01)$ positively affected the frequency of polyps detection. Conclusion-These results suggest that about $30 \%$ of the eligible population would comply at least with sigmoidoscopic screening. The collaboration of family doctors and more widespread public information about the ability to cure colorectal cancer are necessary for better compliance.
\end{abstract}

\section{( $\mathcal{A}$ Epidemiol Community Health 1997;51:453-458)}

About 14000 people die from colorectal cancer every year in Italy, ${ }^{1}$ and about 56000 in the United States. ${ }^{2}$ Among the four high mortality cancers (that is, lung, colorectal, breast, and prostate), colorectal cancer is the only one that has become more curable in the past 25 years and the progressive stages of this cancer are now biologically known. ${ }^{34}$

It has been shown that annual faecal occult blood testing can decrease colorectal cancer mortality by $33 \%,{ }^{5}$ while sigmoidoscopic screening can lead to a reduction in mortality of at least $30-40 \%{ }^{67}$ and colonoscopy every three to five years in the high risk population might result in a reduction of approximately $60-75 \% .^{8}$ Every year in Italy, therefore, 4000 6000 people could, in theory, survive if screening strategies were successfully applied.

Current screening guidelines for colorectal cancer ${ }^{910}$ include stool blood testing performed annually and flexible sigmoidoscopy every three to five years in asymptomatic people over the age of 50 who are at average risk for colorectal cancer. Colonoscopy is recommended for high risk groups, ${ }^{210}$ such as siblings of colorectal cancer patients, who are three times more likely to develop the disease and may account for $12-25 \%$ of all colorectal cancers. ${ }^{811}$

Faecal occult blood testing is the only screening method whose effectiveness has been proved by a randomised trial. ${ }^{5}$ It was suggested, however, that part of the benefit might be due to a random selection for endoscopic examination caused by the low specificity of the method used, ${ }^{12}$ since $38 \%$ of the annually screened participants underwent at least one colonoscopy during the study. ${ }^{5}$

Greenberg and Baron suggested that faecal occult blood testing should be bypassed and endoscopy should be used directly as a screening tool. ${ }^{13}$ Colonoscopy can detect both colorectal cancer and adenomatous polyps with high accuracy, ${ }^{14}$ and colonoscopic removal of polyps decreased the expected incidence of colorectal cancer by $76-90 \%$, as reported by Winawer et al..$^{15}$ Flexible sigmoidoscopy permits a $50-60 \%$ theoretical detection of colorectal cancers and the removal of small polyps in the rectum and the distal part of the large bowel, usually reaching a distance of $40-50 \mathrm{~cm}$ from the anus. ${ }^{16}$ The procedure is simple enough to be performed by nurses, which reduces costs. ${ }^{1718}$ Besides the expense, disadvantages of endoscopic screening include patient discomfort and the risk of bowel perforation (about 1.4 per 10000 sigmoidoscopies and 2 per 1000 colonoscopies). ${ }^{1920}$

There have been few reports of the feasibility of endoscopic screening for colorectal cancer 
to date. ${ }^{2122}$ The Desio screening programme is the first Italian report of colorectal cancer screening based on endoscopy. We report the results obtained in a group of first degree relatives of patients affected by colorectal cancer who were offered screening, including a complete colonoscopic examination, from October 1986 on. The aim of the programme was prevention of colorectal cancer by locating and removing adenomatous polyps in subjects at high risk because of a positive family history, including those who might belong to families affected by familial adenomatous polyposis and hereditary non-polyposis cancer, whose presence in the group could not be excluded on the basis of available information. For that reason, although the age at which screening should be started, in absence of a genetic syndrome, is $5-10$ years younger than the youngest cancer relative or age 40 years, 20 and 75 years of age were chosen respectively as the lowest and highest entry age limit.

\section{Methods}

RECRUITMENT

The names of 536 colorectal cancer patients diagnosed between January 1975 and $\mathrm{De}$ cember 1984 in the public health service region of Desio (Unità Socio Sanitaria Locale 63, Desio, Milan, Italy), which has about 130000 inhabitants, were obtained from the official records of the Regione Lombardia Health System, which comprehensively registers all hospital diagnoses and causes of death. Each patient's identity and cancer diagnosis were verified by examining his/her hospital records.

The names and addresses of family members were obtained from the municipal registry offices and a file was created, consisting of 802 first degree relatives, aged between 20 and 75 years, belonging to 355 families.

Between October 1986 and October 1993 the relatives were repeatedly invited to undergo a screening protocol that included the collection of a personal and family history, faecal occult blood testing, and colonoscopy. The protocol also included a dietary interview with a dietician, measurement of anthropometrical parameters, and 12 blood analyses (results not included in the present report).

The project was presented to and discussed at different meetings with the 110 family practitioners of the public health service region. Their names were obtained from the official records of the Unità Socio Sanitaria Locale 63. They were given literature, material for faecal occult blood testing, and a list of their patients who had been included in the screening programme and whose participation they were requested to solicit.

In addition to the invitations extended by family practitioners, beginning in 1989 , the target subjects were also invited to participate by a letter that stressed the increased risk of disease in consanguineous relatives. These letters were sent out three times over a five year period (almost every second year). Moreover, the 355 families were contacted once by phone and, at their consent, were visited by trained

\section{KEY POINTS}

- Screening of first degree relatives of colorectal cancer patients should include colonoscopy every three to five years starting at the age of 40 years.

- About $30 \%$ of the eligible population in that high risk group would comply with sigmoidoscopic screening at least.

- Compliance was lower in those over 60 years at the start of screening, probably due to fear of a cancer diagnosis and lack of education about prevention.

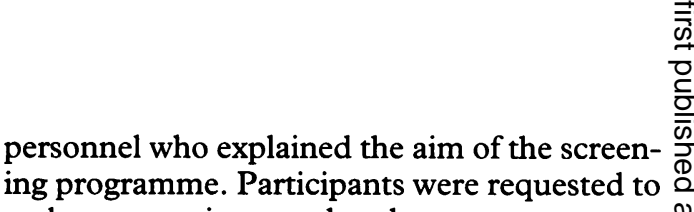
make an appointment by phone.

The family practitioners were kept informed $\overrightarrow{0}$ periodically on the progress of the programme.

\section{PROCEDURE}

Personal and family history

The personal and family history of each par ticipant were collected by trained medical personnel, who filled out a questionnaire. Family $\omega$ history investigation included information con- 음 cerning stomach, breast, lung, endometrium, ovary, and urinary tract cancers.

\section{Endoscopy}

After receiving their informed consent, colon- ? oscopy was performed. The participants were supplied with full bowel preparation instructions according to the standard procedure in use at the Desio Endoscopy Unit. In 198790 , this required a residue-free diet in the 48 hours before the examination, together with saline purgatives and voiding enemas. From 1991 on, however, a polyethylene glycol electrolyte lavage solution was used. Patients received $20 \mathrm{mg}$ of butylscopolamine bromide by intravenous injection before the examination. Analgesic premedication before colonoscopy was not in use at the Desio Endoscopy Unit during the years of the screening programme. The equipment used was a standard Pentax $(160 \mathrm{~cm})$ fiberoptic instrument in the years 1987-90 (Pentax -API SpA, Milan, Italy) and $>$ an apparatus for video-endoscopy (C 3800 and C 3810, Pentax-API SpA, Milan, Italy) sub- N sequently. The examinations were performed by the same two endoscopists in turn. When a colonoscopy was incomplete and the subject was over 50 in age, a double contrast barium enema was recommended.

\section{Statistical analysis}

Results were processed by a $S P S S / P C+$ package. The $\chi^{2}$ test (with the appropriate degrees of freedom) was used to assess the differences between groups; Fisher's exact test (two tailed) was used when the minimum expected frequency was less than 5 . A p value $<0.05$ was regarded as significant. 


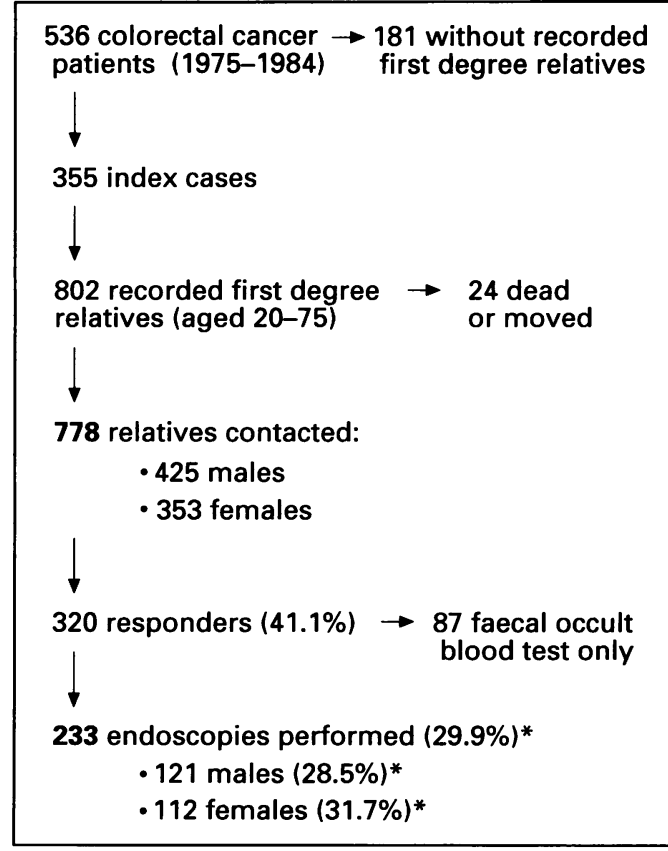

*Percentage of subjects screened versus those contacted.

Figure 1 Compliance with endoscopic screening for colorectal cancer in Desio, Italy.

\section{Results}

COMPLIANCE WITH COLONOSCOPIC SCREENING As summarised in figure 1, 778 living, first degree relatives of the 355 colorectal neoplasm patients were contacted. Altogether 425 of them were males and 353 were females.

After seven years, 233 subjects from the group $(29.9 \%)$ had complied with the screening programme and had undergone at least one endoscopy; 87 more persons (11.2\%) had had a faecal occult blood test without endoscopy.

Consent was greatest in the first two years (1987-88), when 187 subjects took part in screening and 108 endoscopies were performed. It fell during subsequent recalls - there were 69 participants in 1989-90 (65 endoscopies) and 64 in 1991-93 (60 endoscopies). Gender did not affect participation. The mean age at the first endoscopy was 44.3 in males (range: $26-68$; SD: 10.8 ) and 45.8 in females (range: 23-74; SD: 11.2).

Compliance with endoscopic screening in relation to the age at the beginning of the programme was evaluated. Thirty six out of 205 subjects aged $20-29$ at 10/01/1986 (17.6\%) underwent endoscopy. Significant differences in participation were observed in older subjects

Table 1 Compliance with endoscopic screening for colorectal cancer in relation to age at the start of the programme

\begin{tabular}{lcccc}
\hline \multicolumn{5}{c}{ Age $(y)$ at start of screening* } \\
\cline { 2 - 5 } & $30-39$ & $40-49$ & $50-59$ & 60 \\
\hline Screened (no (\%)) & $71(39.4)$ & $61(36.3)$ & $50(33.1)$ & $15(20.3)$ \\
Contribution to $\chi^{2}(3 \mathrm{df})$ & 1.34 & 0.18 & 0.07 & 4.28 \\
Not screened (no (\%)) & $109(60.6)$ & $107(63.7)$ & $101(66.9)$ & $59(79.7)$ \\
Contribution to $\chi^{2}(3 \mathrm{df})$ & 0.70 & 0.10 & 0.04 & 2.25 \\
Total (no (\%)) & $180(100.0)$ & $168(100.0)$ & $151(100.0)$ & $74(100.0)$ \\
Contribution to $\chi^{2}(3 \mathrm{df})$ & 2.04 & 0.28 & 0.11 & 6.53 \\
& $\chi^{2}(3 \mathrm{df})=8.96$ & & $\mathrm{p}<0.05$ & \\
\hline
\end{tabular}

*Age of first degree relatives at 10/01/1986. Among people aged 20-29, 36 out of 205 subjects $(17.6 \%)$ took part in the screening. (table 1), with the highest compliance in the age groups 30-39 and 40-49, lower compliance in the group 50-59, and a drop in people aged 60 or older.

Education level in the screened group was compared with that of the general population (about 4000000 people) in the province of Milan, as per the 1991 national census data. ${ }^{23}$ No significant difference was seen when participants were stratified by age.

\section{ANATOMICAL SITE REACHED BY ENDOSCOPY}

Colonoscopy was performed up to the caecum in 48 of 223 subjects $(20.6 \%)$, including those who were found positive for colorectal neoplasms. In the remaining 185 participants $(79.4 \%)$, the examination was terminated at different bowel sites for the following reasons:

- Discomfort which negatively affected patient compliance (54\%),

- Poor bowel preparation (40\%),

- Risk of complications because of technical difficulties $(6 \%)$.

The transverse colon was reached in 30 subjects $(12.9 \%)$, the splenic flexure in $99(42.5 \%)$ and the descending colon in $56(24.0 \%)$.

FAECAL OCCULT BLOOD TESTING RESULTS

Among the 233 participants who underwent endoscopic screening, the faecal occult blood tests yielded 1 true positive (in : subject with a Dukes's A cancer of the transverse colon), 1 false positive (in a subject without neoplasms), 3 false negatives (in subjects whose endoscopy disclosed adenomatous polyps measuring $10 \mathrm{~mm}$ in diameter or more), and 228 true negatives. The subjects with polyps less than $10 \mathrm{~mm}$ in diameter were not regarded as false negatives, even though none of them tested positive, because their lesions were considered to be bleeding only intermittently. ${ }^{24}$ Test sensitivity and specificity were $25 \%$ and $99 \%$ respectively.

Among the 87 subjects who agreed to undergo faecal occult blood testing but refused endoscopy, two tested positive with Haemoccult II. One of them underwent an operation for colon cancer two years later, the other one was lost to follow up.

\section{THE NEOPLASTIC FINDINGS AT SCREENING}

Two subjects with cancer (frequency $=0.9 \%$ ) and 24 with adenomatous polyps (frequency= $10.3 \%$ ) were found among the 233 screened participants. Twenty seven adenomatous polyps were found (more than 1 finding per subject). The anatomical site and pathology of the neoplastic findings are shown in table 2 .

A Dukes's A cancer of the transverse colon was found in a subject who also had two tubular polyps. The polyps were found in the sigma and descending colon respectively. Carcinoma "in situ" was seen in a $2.5 \mathrm{~cm}$ large, villotubular adenoma.

A single tubular adenoma located in the ascending colon was found in a participant who 
Table 2 Anatomical site and pathology of the neoplastic findings* in 26 subjects

\begin{tabular}{|c|c|c|c|c|c|}
\hline \multirow[t]{2}{*}{ Pathology } & \multicolumn{5}{|c|}{ Anatomical site } \\
\hline & Rectum & Sigma & $\begin{array}{l}\text { Descending } \\
\text { colon }\end{array}$ & $\begin{array}{l}\text { Transverse } \\
\text { colon }\end{array}$ & $\begin{array}{l}\text { Ascending } \\
\text { colon }\end{array}$ \\
\hline Cancer Dukes's A & - & - & - & 1 & - \\
\hline Carcinoma in situ & 1 & - & - & - & - \\
\hline Villo-tubular adenoma & - & 5 & 2 & - & - \\
\hline Tubular adenoma & - & 12 & 7 & - & 1 \\
\hline Total & 1 & 17 & 9 & 1 & 1 \\
\hline No of screened subjects $†$ & 233 & 233 & 177 & 78 & 48 \\
\hline Frequency (\%) & 0.4 & 7.3 & 5.1 & 1.3 & 2.1 \\
\hline
\end{tabular}

* More than 1 finding per subject.

† Number of subjects whose corresponding anatomical site was examined.

Table 3 Adenomatous polyps in relation to age and family history

\begin{tabular}{llll}
\hline Age $(y)^{*}$ & \multicolumn{3}{l}{ Positive versus screened subjects (\%) } \\
\cline { 2 - 4 } & $\begin{array}{l}\text { 1 relative } \\
\text { affected }\end{array}$ & $\begin{array}{l}\text { 2 relatives } \\
\text { affected }\end{array}$ & Total \\
\hline Males & & & \\
$20-39$ & $0 / 40$ & $1 / 11(9.1)$ & $1 / 51(2.0)$ \\
$40-59$ & $8 / 44(18.2)$ & $3 / 15(20.0)$ & $11 / 59(18.6)$ \\
60 & $2 / 4(50.0)$ & $4 / 6(66.7)$ & $6 / 10(60.0)$ \\
All ages & $10 / 88(11.4)$ & $8 / 32(25.0)$ & $18 / 120(15.0)$ \\
Females & $0 / 25$ & $0 / 9$ & $0 / 34$ \\
$20-39$ & $1 / 48(2.1)$ & $5 / 17(29.4)$ & $6 / 65(9.2)$ \\
$40-59$ & $0 / 9$ & $0 / 3$ & $0 / 12$ \\
60 & $1 / 82(1.2)$ & $5 / 29(17.2)$ & $6 / 111(5.4)$ \\
All ages &
\end{tabular}

* Age of the participants at the time they underwent endoscopy.

had consented to undergo colonoscopy up to the caecum.

FREQUENCY OF POLYPS IN RELATION TO SEX, AGE, AND FAMILY HISTORY

The subject with Dukes's A cancer was a 56 year old man, while the in situ carcinoma was found in a 31 year old woman. They both had only one first degree relative with colorectal cancer.

The influence of gender, age, and family history on the frequency of adenomatous polyps in the group of participants was investigated (table 3), although the real prevalence of neoplastic findings could not be calculated because of the incompleteness of endoscopic examination.

No cases of familial adenomatous polyposis were encountered. All the subjects who had two or more colorectal cancer patients in their family history $(n=61)$ were grouped separately from those who had only one $(n=170)$. The kinship of 15 subjects included not only two or more members with colorectal cancer but also two or more members with cancers at other sites (stomach, breast, lung, or ovary). Their eight families did not strictly fulfil the requirements for the clinical diagnosis of hereditary nonpolyposis colorectal cancer, however, ${ }^{25}$ so they were not grouped apart.

Polyps were found more frequently in men than in women $(p<0.05)$. In male subjects a higher frequency of adenomatous polyps was associated with increasing age $(\mathrm{p}<0.01)$. Polyps were more frequently found in subjects with two or more relatives affected by colorectal cancer than in subjects who had only one, but the difference reached a statistical significance only for women $(p<0.01)$.

\section{Discussion}

Although endoscopic screening begins to be $c$ taken into account as a promising tool for $\frac{\Pi}{0}$. colorectal cancer prevention, ${ }^{182627}$ its im- 음 plementation poses many problems including the cost benefit ratio, the availability of the 으 required skill and technology, and a good level of compliance with the proposed procedure by the target population.

The present screening programme addressed high risk consanguineous relatives of colorectal $\underset{I}{\stackrel{F}{*}}$ cancer patients. The prevalence of adenomatous polyps found in this group agreed $\frac{\stackrel{\varpi}{5}}{5}$ with that obtained by Rozen in a screening programme for colorectal neoplasm, where $\stackrel{\vec{P}}{+}$ different screening methods (faecal occult ${ }^{\circ}$ blood testing, flexible sigmoidoscopy, colon- $\frac{\bar{\sigma}}{\overline{0}}$ oscopy) were used according to the degree of cancer risk. ${ }^{28}$

After 7 years of screening, the compliance of the target population was $41.1 \%$ for faecal $\vec{\circ}$ occult-blood test and $29.9 \%$ for endoscopy. The percentages of participants are con- $\vec{\omega}$ siderably lower than those reported by Stephenson et al, ${ }^{22}$ who performed colonoscopy in $\stackrel{\Phi}{\supset}$ 107 out of 154 (69\%) first degree relatives of $\vec{v}$ colorectal cancer patients and sigmoidoscopy is in 30 out of $64(47 \%)$ spouses. In their pro- of gramme, a relatively short time had elapsed $\omega$ since the index cases' diagnosis of colorectal 을 cancer had been established, a factor that could $\rightarrow$ have favourably affected the outcome. Nevertheless, the level of compliance with endoscopy achieved in the present screening programme was close to that reported for sigmoidoscopy $\vec{\bullet}$ in two other studies- $31 \%$ in the Kaiser multi- . phase evaluation study ${ }^{21}$ and $24 \%$ reported by Dietrich et al. ${ }^{29}$

Gender did not affect the propensity to undergo screening in this study. However, significant differences in participation were seen in relation to age. The decrease in compliance recorded in subjects who were over 60 at the start of the screening programme is worrisome as colorectal cancer incidence rates rise with ageing. ${ }^{30}$ Possible explanations for that finding could be, firstly, better education in maintaining healthy lifestyles in younger people and, secondly, the fear, which could increase with ageing, of getting an advanced diagnosis of a disease thought to be incurable.

The sensitivity of faecal occult blood testing 음 by Haemoccult II (without rehydration) ranges $D$ from 80 to $31 \%$ for cancers, ${ }^{51924}$ and is thought to be about $10 \%$ for large adenomas. ${ }^{19}$ The $N$ sensitivity obtained in the Desio screening programme was rather low, as expected in $\mathrm{N}$ asymptomatic people, and it is improbable that $\omega$ the faecal occult blood test results exerted any positive influence on the participants' propensity to undergo endoscopic screening. It is remarkable that 2 of the 320 responders, who consented to undergo faecal occult blood testing but refused endoscopy, persisted in refusing it even though their tests turned out to be positive.

Difficulties in completing the endoscopic examination up to the caecum were encountered both in men and in women; it is probable that better results would have been achieved if 
analgesic agents had been used, since most of the examinations were stopped when the patients judged the discomfort to be unbearable. Nonetheless, colonoscopy could be performed in subjects found positive for colorectal neoplasms, either immediately or at a second recall. That was certainly due to the propensity of endoscopists to complete exploration up to the caecum or not, taking into account that the risk of complications increases with the depth of exploration. ${ }^{920}$ Nevertheless, it also suggests that being aware of personal risk can positively affect the compliance of participants.

During the seven years of the Desio screening programme, one Dukes's A carcinoma and one villo-tubular adenoma with carcinoma in situ were detected among 233 participants. Both the neoplasms were in the early stages, as would be expected in a screening programme of asymptomatic people. Bertazzi et al found 9 colorectal cancers per 31384 person-years in average risk men and women aged 20-74 living in the area north of Milan that includes Desio, ${ }^{31}$ while Ponz de Leon et al reported a total crude incidence of 52.8 colorectal cancer cases per 100000 person-years in the northern Italy district of Modena..$^{32}$ On the basis of both authors' data and considering the increase in colorectal cancer risk associated with a family history, the expected number of carcinomas in the group that underwent endoscopic examination varied from 0 to 3 . Owing to the incompleteness of colonic examination, the possibility that cancers proximal to the splenic flexure had gone undetected cannot be excluded (the continuing follow up of cancer diagnosis, for the moment, has reached the year 1990).

The frequency with which polyps were found in the Desio group is comparable to the prevalence reported by Rozen and by Stephenson et $a^{8822}$ when corresponding age groups are taken into account. Other authors, ${ }^{3334}$ whose data were based on full bowel colonoscopy, reported higher prevalence rates for adenomatous polyps in subjects comparable to those of the present study for age, gender, and family history.

Although the real prevalence of adenomatous polyps in the Desio group could not be assessed, the findings of the screening programme seem to confirm the data of different authors, ${ }^{28323335}$ who have reported an increasing prevalence with ageing, and a higher prevalence of adenomatous polyps in males than in females and in subjects with two or more colorectal cancer patients in their family history than among those with only one. ${ }^{35}$

The results of the Desio screening programme suggest that about $30 \%$ of the eligible population would consent to undergo colorectal cancer screening by endoscopic examination. In other words at least $1000-1500$ deaths could be prevented in Italy in one year.

Nevertheless, the Desio endoscopic screening results suggest that before colorectal cancer screening by endoscopy can be successfully implemented in a large eligible population, widespread information must be supplied to the public about the ability to cure colorectal cancer in its early stages and the benefit of detecting adenomatous polyps in order to improve the acceptability of such a screening method. An example among cancer prevention tools could be the publicity given to mammography in the USA, where the percentage of women who had undergone a mammogram at least once increased from $13-17 \%$ in 1978 to $74 \%$ in $1992 .{ }^{36}$ As calculated by Ransohoff, ${ }^{27}$ the cost per life saved by a one time colonoscopic screening is comparable with that of mammographic screening, and the higher curability of early colorectal cancer in comparison with breast cancer ${ }^{3}$ prompts such an effort.

We thank the family practitioner doctors of the "Associazione Medici Desio" for their contribution to the study.

Funding: supported by a research grant no 2567/127 from the Regione Lombardia, Milan, Italy

Regione Lombardia, Milan,
Conflicts of interest: none

1 Sistema Statistico Nazionale-Istituto Nazionale di Statistica. Cause di morte-anno 1990. Roma: ISTAT, 1994;6.

2 Toribara NW, Sleisenger MH. Screening for colorectal can cer. $N$ Engl f Med 1995;332:861-67.

3 Beardsley T. A war not won. Sci Am 1994;270:118-26.

4 Vogelstein B, Fearon ER, Hamilton SR, et al. Genetic Vogelstein B, Fearon ER, Hamilton SR, et al. Genetic
alterations during colorectal-tumor development. $N$ Engl $\mathcal{F}$ alterations during color

5 Mandel JS, Bond JH, Church TR, et al. Reducing mortality from colorectal cancer by screening for faecal occult blood. $N$ Engl f Med 1993;328:1365-71.

6 Selby JV, Friedman GD, Quesenberry CP, Weiss NS. A case-control study of screening sigmoidoscopy and mortality from colorectal cancer. $N$ Engl $f$ Med 1992;326: 653-57.

7 Newcomb PA, Norfleet RG, Storer BE, Surawicz TS, Marcus PM. Screening sigmoidoscopy and colorectal cancer mortality. F Natl Cancer Inst 1992;84:1572-5.

8 Eddy DM, Nugent FW, Eddy JF, et al. Screening for colorectal cancer in a high-risk population. Results of a mathrectal cancer in a high-risk population. Results of

9 American Cancer Society. Summary of current guidelines for Ame cancer-related check-up: recommendations. New York: the cancer-related check-up: recom

10 Winawer SJ, St John DJ, Bond JH, et al. Prevention of Winawer SJ, St John DJ, Bond $\mathrm{JH}$, et al. Prevention of York: WHO Collaborating Center for the Prevention of Colorectal Cancer, Memorial Sloan-Kettering Cance Center, New York, NY 10021, USA. Bull World Health Organ 1995;73:7-10.

11 Sandler RS, DeVellis BM, Blalock SJ, Holland KL. Participation of high-risk subjects in colon cancer screening. Cancer 1989;63:2211-15.

12 Lang CA, Ransohoff DF. Faecal occult blood screening. Is mortality reduced by chance selection for screening colonoscopy? FAMA 1994;271:1011-13.

13 Greenberg ER, Baron JA. Prospects for preventing colorectal cancer death. I Natl Cancer Inst 1993;85:1182-4.

14 Warneke J, Petrelli N, Herrera L, Nava H. Accuracy of colonoscopy for the detection of colorectal polyps. Dis Colon Rectum 1992;35:981-5.

15 Winawer SJ, Zauber AG, Ho MN, et al. Prevention of colorectal cancer by colonoscopic polipectomy. The $\mathrm{Na}$ tional Polyp Study Workgroup. $N$ Engl $\mathcal{f}$ Med 1993;329. 1977-81.

16 Winawer SJ, Schottenfeld D, Flehinger BJ. Colorectal cance screening. $\mathcal{F}$ Natl Cancer Inst 1991;83:243-53.

17 Maule WF. Screening for colorectal cancer by nurse en doscopists. N Engl f Med 1994;330:183-7.

18 Ransohoff DF, Lang CA. Sigmoidoscopic screening in the 1990s. FAMA 1993;269:1278-81.

19 Ransohoff DF, Lang CA. Screening for colorectal cancer. $N$ Engl f Med 1991;325:37-41.

20 Solomon MJ, McLeod RS. Screening strategies for colorectal cancer. Surg Clin North Am 1993;1:31-45.

21 Friedman GD, Collen MF, Fireman BH: Multiphase health checkup evaluation: a 16-year follow-up. $\mathcal{f}$ Chronic Dis 1986;39:936-9.

22 Stephenson BM, Murday VA, Finan PJ, Quirke P, Dixon MF, Bishop DT. Feasibility of family based screening for MF, Bishop DT. Feasibility of family based screening for
colorectal neoplasia: experience in one general surgical

23 Sistema Statistico Nazionale-Istituto Nazionale di Statistica. Popolazione e abitazioni. Fascicolo provinciale Milano. $13^{\circ}$ censimento generale della popolazione e delle abitazioni, 20 ottobre 1991. Roma: ISTAT, 1994.

24 Kimmig JM, Strauch M, Hallen M. Negative Haemoccul test in malignant and premalignant lesions of the colon Validation of the Haemoccult test with total colonoscopy. Endoscopy 1989;21:136-40.

25 Vasen HFA, Mecklin JP, Meera Khan P, Lynch HT. The international collaborative group on hereditary non-polyposis colorectal cancer: Dis Colon Rect 1991;34:424-5.

26 Sox HC. Preventive health services in adults. $N$ Engl $\mathscr{f} \mathrm{Med}$ 1994;330:1589-95.

27 Ransohoff DF, Lang CA. Cost-effectiveness of one-time 
colonoscopy screening to reduce colorectal cancer mortality. Gastroenterology 1994;106:Suppl:A24

28 Rozen P. Screening for colorectal neoplasia in the Tel Aviv area: cumulative data $1979-89$ and initial conclusions. Is f.Med Sci 1992;28(1 Suppl):4-7.

29 Dietrich AJ, O'Connor GT, Keller A, Carney PA, Levy $D$, Whaley FS. Cancer: improving early detection and prevention: a community practice randomised trial. $B M \mathcal{F}$ 1992;304:687-91.

30 Bronchud MH. Colorectal cancer. State of the art. Europ Cancer News 1993;6:1-6.

31 Bertazzi PA, Pesatori AC, Consonni D, Tironi A, Landi MT, Zocchetti C. Cancer incidence in a population accidentally exposed to 2,3,7,8-tetrachlorodibenzo-para-dioxin. Epidemiology 1993;4:398-406.

32 Ponz de Leon M, Antonioli A, Ascari A, Zanghieri G,
Sacchetti C. Incidence and familial occurrence of colorectal cancer and polyps in a health-care district of northern Italy. Cancer 1987;60:2848-59.

33 Johnson DA, Gurney MS, Volpe RG, et al. A prospective study of the prevalence of colonic neoplasms in asymptomatic patients with an age-related risk. Am $\mathcal{f}$ Gastroenterol 1990;85:969-74.

34 Meagher AP, Stuart M. Colonoscopy in patients with a family history of colorectal cancer. Dis Colon Rectum 1992; 35:315-21.

35 Rex DK, Lehman GA, Ulbright TM, et al. Colonic neoplasia in asymptomatic persons with negative faecal occult blood tests: influence of age, gender, and family history. $A m \mathcal{F}$ Gastroenterol 1993;88:825-31.

36 Dodd GD. Screening for breast cancer. Cancer 1993;72(3 Suppl):1038-42. 